\title{
Os saberes do trabalho: uma análise do caso dos mecânicos frente à reestruturação da indústria da reparação automotiva
}

\section{Laura Senna Ferreira}

Os saberes do trabalho: uma análise do caso dos mecânicos frente à reestruturação da indústria da reparação automotiva

Resumo: O propósito deste artigo é desenvolver uma reflexão sobre a natureza dos saberes associados ao trabalho, considerando as especificidades dos conhecimentos tácitos que compõem os ofícios. A partir do caso dos mecânicos automotivos da cidade de Porto Alegre (RS), observa-se de que maneira o ingresso na profissão de homens provenientes de instituições de ensino altera os modos de vida e trabalho imperantes. Indica-se que as transformações recentes no ofício ocorrem tanto no plano técnico como no cultural. Analisam-se, na indústria da reparação automotiva, as interfaces entre a admissão dos mais escolarizados, as transformações nos saberes e a presença do discurso do empreendedorismo.

Palavras-Chave: ofício. Saberes tácitos. Conhecimento formal. Empreendedorismo.

\section{Knowledge work: an analysis of mechanics front the restructuring of the car industry}

Abstract: The central issue of the article is thinking about the nature of knowledge associated to work, considering specificity of tacit knowledge that make up trades. The study considers, based on the case of car mechanics in city of Porto Alegre (RS), the way that admission in this profession of men from educational institutions changes the way of life and work prevailing in the sector. The article exposes that the recent changes in the trade happen both on technical and cultural plan. The text analyses in the automotive repair industry the connection among the admission of more educated guys, the change on knowledge and the presence of entrepreneurship discourse.

Key-Words: Environmental education. Attitudes. Behavior.

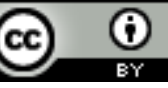

Esta obra foi licenciada sob uma Licença Creative Commons - Atribuição 3.0 Não Adaptada. 


\section{Introdução}

No curso das transformações recentes no mundo produtivo os trabalhadores se deparam com a necessidade de adquirirem outras e renovadas qualificações. Desde o momento em que as empresas passaram a adotar os paradigmas da empregabilidade e do empreendedorismo, eles foram convidados a assumirem posturas e comportamentos mais flexíveis e adaptados às novas demandas do mercado de trabalho. As posições sociais de cada um encontram-se, assim, abaladas pelas dinâmicas globais da economia, fazendo com que seja preciso responder às transformações, argumentar e justificar sobre os seus afortunados ou precários lugares no mundo.

Num cenário de mudanças técnico-organizacionais que recoloca a subjetividade do trabalhador como elemento chave na busca por produtividade, o domínio cognitivo dos agentes da produção passa a ser fundamental para a competitividade dos empreendimentos. Por conseguinte, os saberes do trabalho ascendem a outro patamar, tanto em termos técnicos como no que diz respeito ao status, tornando-se parte do cálculo econômico empresarial.

Com o advento das tecnologias, especialmente, da microeletrônica, são exigidos novos conhecimentos da força de trabalho. Em função disso, ramos que até recentemente eram abertos aos "práticos", passam a ser monopólio dos "estudados", tendencialmente mais dispostos à racionalização dos processos de trabalho e à adoção de posturas empreendedoras.

O presente estudo baseia-se em pesquisa realizada na cidade de Porto Alegre (RS), quando foram realizadas, em diferentes momentos entre os anos de 2010 e 2013, investigação em jornal do segmento dos serviços automotivos, etnografia nas oficinas e entrevistas junto a mecânicos e membros de entidades influentes no setor.

Tendo em vista o exposto, o presente artigo divide-se em três seções. Primeiramente, apresenta-se o debate teórico que serviu de base para o estudo. A seguir, analisa-se o caso específico dos saberes associados ao ofício do mecânico automotivo. Por fim, considera-se de que modo as mudanças no mundo do trabalho, principalmente aquelas associadas às noções de empregabilidade e empreendedorismo, alteram os modos de ser do ofício.

\section{Os saberes cotidianos e do trabalho}

$\mathrm{Na}$ sociedade moderna, do ponto de vista hegemônico, compreendem-se como legítimos os saberes que são frutos de uma reflexão pura, considerada tanto mais precisa quanto mais distante das mãos e das emoções dos homens. Em Descarte (1596-1650), no âmbito de uma racionalidade iluminada, mente e corpo, sujeito e objeto, eu e outro, passam a ser dicotômicos. O Cogito, ergo sum (penso, logo existo) é o modelo do pensador individualizado, solitário, soberano e independente das relações sociais e culturais contaminadoras do verdadeiro conhecimento, que é considerado como uma construção exclusivamente mental-cognitiva. Na perspectiva cartesiana, o conhecimento é concebido como tal quando se coloca de forma impessoal e objetiva, perdendo-se, assim, toda e qualquer dimensão sociocultural dos saberes.

Em outra acepção, a qual explora a natureza relacional e a conexão entre "saber, vida e contexto", o primeiro é entendido como heterogêneo e entrelaçado às múltiplas 
racionalidades (JOVCHELOVITCH, 2008). Segundo Jovchelovitch (2008, p.83), a negação de um sistema de conhecimento constitui "atos de violência" que infringem mundos pessoais, sociais e culturais, inferiorizam determinadas coletividades e ameaçam a identidade dos sujeitos.

Grupos com características semelhantes constroem um repertório comum de saberes, conectados às suas experiências de vida. Os contextos e as formas de produzilos são diversos e resultam tanto da relação intersubjetiva dos homens entre si como das conexões que estabelecem com os objetos que compõem o "mundo das coisas", o que significa dizer que o conhecimento é também produzido no manuseio dos objetos, numa permeabilidade entre "coisas" e pessoas (APPADURAI, 1986).

Em Sennett (2009, p.17) esta união entre ideias e objetos, assim como aquela que ocorre entre mente e corpo, realiza-se no artífice, ultrapassando a divisão entre Animal laborens e Homo faber:

Esta divisão parece-me falsa porque menospreza o homem prático - ou a mulher - que trabalha. O animal humano que é Animal Laborens é capaz de pensar; as discussões sustentadas pelo produtor podem ocorrer mentalmente com os materiais... o pensamento e os sentimentos estão contidos no processo de fazer.

Na civilização ocidental "a técnica tem má fama; pode parecer destituída de alma. Mas não é assim que é vista pelas pessoas que adquirem nas mãos um alto grau de capacitação. Para elas, como bem sabem, por exemplo, os músicos, os cozinheiros e os programadores de softwares, a técnica estará sempre intimamente ligada à expressão" (SENNETT, 2009, p.170). Em outras palavras, as mãos possuem íntimas ligações com o cérebro e com o pensamento, num movimento no qual pergunta-se tanto "Por quê?" quanto "Como?" (SENNETT, 2009).

O debate, assim posto, acaba por colocar em xeque as dicotomias mais elementares da sociedade moderna, destacando-se entre elas as divisões entre trabalho manual e intelectual, inteligentes e não inteligentes, alma e corpo, concepção e execução. Nesses termos, a forma de saber que integra mãos e pensamentos remete a uma aprendizagem artesanal,

A dos "companheiros", que repousa na transmissão de saberes e know-how de ofício no seio de um "meio" organizado por regras sociais, modelos de condutas, formas de identificação e rituais de iniciação. No início encontra-se a imersão num processo de trabalho, a aprendizagem pela prática, com os outros, pelo e sobre o "terreno", isto é, um contexto específico de ação. É a imitação dos antigos, a mimesis que gera "saberes de ação", um conhecimento prático e incorporado que é apenas uma "teoria-em-ato", um conjunto de saberes vindos da experiência e que não se sabe que se sabe (DUBAR, 2009, p.212).

O conhecimento prático envolve desempenho sensorial e percepção. Todavia, "o envolvimento do corpo, ainda que este seja criador da própria inteligência prática, não implica ausência de pensamento" (DEJOURS, 1993, p.288). 
Aqui reina o "jogo rápido", a malícia, a trapaça, a esperteza, a astúcia. A justificativa, a explicação, a elucidação, a legitimação e a análise só intervêm posteriormente ao sucesso... Esta inteligência é fundamentalmente uma "inteligência ardilosa" (DEJOURS, 1993, p.289).

A “inteligência prática", que está no cerne do ofício, não raro serve de base para as ações que bloqueiam tanto as tentativas de padronização e normatização dos saberes como as que se referem a racionalização do trabalho.

\section{Desigualdades de acesso aos conhecimentos e resistência à racionalização dos saberes}

Enquanto "saber em ato", o domínio tácito, apesar de sua capacidade de organização conceitual, é "circunscrito, quer dizer, carece de poder de generalização" (FRANZOI, 2009, p.191), e opera como "conhecimento que não se aprende na escola" e, no qual, "se desenvolve o lado contingencial do modo de raciocinar" (SZNELWAR; MASCIA, 1997, p.221).

Apesar de todas as mudanças no mundo do trabalho com a incorporação de novas tecnologias e métodos de gestão empresarial, a dimensão da inteligência dos trabalhadores permanece (KUENZER, 2003), reforçando, entre eles, a "compreensão de que existe um saber que é patrimônio de uma classe, uma classe que produz" (FRANZOI, 2009, p.197-198). As divisões de classe que contribuem para a construção de fronteiras entre os saberes práticos e teóricos colaboram para a elaboração de perspectivas culturais distintas acerca do "valor" dos conhecimentos. Aquilo que foi em um determinado momento uma limitação de classe, quer dizer, o acesso circunscrito aos saberes práticos, torna-se, enquanto manifestação das contradições, fonte de orgulho e status entre os trabalhadores.

Nas sociedades modernas, o trabalho que alguém desempenha é um dos principais determinantes do seu lugar social. E o domínio dos saberes oficiais tem funcionado como condição de acesso às posições privilegiadas. No que concerne a divisão social do trabalho, a separação entre trabalho intelectual e manual opera como sinal, a partir do qual se reconhece a classe social do sujeito, sendo reservado às classes populares as ocupações subalternas que são, predominantemente, as manuais.

O caráter socialmente determinado (classificação) da hierarquização dos trabalhos, o qual dá origem às diferenças salariais, "não se sustenta pela análise dos conteúdos distintos dos trabalhos, uma vez que não há critérios de valoração inerentes à sua própria natureza que justifiquem a conversão das diferenças em desigualdades" (KUENZER, 2011, p.130).

Em tais circunstâncias impõem-se um dilema para boa parte dos trabalhadores: por um lado, eles são impedidos de ter acesso aos saberes escolares; por outro, sofrem com a desvalorização (expressa, por exemplo, nos baixos salários) dos saberes elaborados a partir da experiência. Na organização das empresas, apesar de se utilizar os saberes de todos agentes produtivos, as hierarquias entre trabalhadores, em termos de cargos, funções e salários, são comumente associadas à escolaridade.

Outro aspecto relevante refere-se ao fato de que a concepção de que a sociedade está dividida entre os que são "bons com as mãos" e os que são "bons com a cabeça" faz 
com que, muitas vezes, os trabalhadores supervalorizem as atividades manuais e desdenhem as qualificações adquiridas na aprendizagem formal (WILLIS, 1977, p.148). Dessa maneira, construções culturais que decorrem da autoestima e do senso de dignidade entre os homens que trabalham, contribuem, contraditoriamente, para a reprodução da sua própria condição de inferioridade, distanciando-os ainda mais do acesso aos diplomas mais valorizados.

Para Willis (1977), a valorização do trabalho manual é uma reelaboração cultural que ocorre a partir de carreiras que estão bloqueadas, já que, desde o início, os jovens das classes populares, devido à necessidade imediata de dinheiro, são formados para serem trabalhadores, para o trabalho manual, não importando qual seja ele.

Apesar disso, não são poucos os casos nos quais os trabalhadores realizam investimentos escolares baseados na crença do poder formal da escola, visando com isso melhorar sua posição e capacidade de competição (CUNHA; CUNHA, 2003, p.11). Nesse esforço, a passagem pela educação profissional se coloca como um dos percursos mais plausíveis para boa parte da classe trabalhadora.

No caso brasileiro, o ensino dos ofícios esteve desde o início associado às iniciativas do Estado e da sociedade civil, que se voltaram a ensinar uma profissão aos considerados "deserdados de fortuna". No período do império, as justificativas mais frequentes para isso versavam sobre a necessidade de

a) imprimir a motivação para o trabalho; b) evitar o desenvolvimento de idéias contrárias à ordem política... c) propiciar a instalação de fábricas que se beneficiariam da existência de uma oferta de força de trabalho qualificada, motivada e ordeira; e d) favorecer os próprios trabalhadores, que passariam a receber salários mais elevados... Ao fim do Império, com a chegada ao Brasil dos padres salesianos, um novo elemento ideológico foi incorporado a esse conjunto - o do ensino profissional como antídoto ao pecado (CUNHA, 2000, p.92).

Com isso, no império, institucionalizava-se uma divisão social do trabalho, que será reforçada, na República, transformando-se em política de Estado. Em 1909, o então presidente Nilo Peçanha cria, em quase todos os Estados, as Escolas de Aprendizes Artífices, dando início a atuação direta do governo Federal na área de formação profissional.

Adiante, com a adesão, pelo Estado Novo de um projeto industrialista de desenvolvimento, a educação profissional passou a ser sistematicamente pensada em nível nacional. É quando o governo lança o Decreto-lei de 1939, que obrigava as empresas a manterem cursos de aperfeiçoamento profissional, de modo a garantir uma formação básica àqueles que não dariam continuidade aos estudos.

É com esse mesmo espírito que é criado o SENAI, em 1942. A agência torna-se um marco da ingerência da empresa e do Estado no ensino profissional. A partir daí o governo faz com que os empresários, através da contribuição compulsória, assumam parte do ensino profissional (CUNHA, 2000). Desse modo, no período do presidente Getúlio Vargas se estabelece de uma vez por todas a estrutura elitista do ensino brasileiro:

De um lado, um ensino secundário seletivo, enciclopédico, rígido, uniforme e intelectualista, destinado a capacitar estudantes para o ingresso no curso superior, onde se consolidaria a formação das 
"individualidades condutoras". De outro lado, um ensino profissional, "destinado às classes menos favorecidas", como dizia a carta constitucional de 1937 (MACHADO, 1989, p.36).

Até a metade da década de 1990 o sistema de educação profissional brasileiro era basicamente o herdado dos anos de 1940: redes federais e estaduais de escolas técnicas, Sistema S (SENAI, por exemplo) e escolas isoladas. Em 1995 surgiu uma nova proposta política: o Ministério do Trabalho e o Ministério da Educação editam um documento firmando que a educação, em todos os seus formatos, não deve mais ser centrada "no treinamento específico para a realização de tarefas, mas (...) numa base de conhecimentos, atitudes e habilidades que só podem ser obtidas através de uma sólida educação geral" " . A lei em questão toma por base a reestruturação produtiva dos anos 1990, e conclui pela necessidade de construir uma estrutura educacional flexível, destacando a necessidade de articulação com o Sistema S.

A complexidade do momento reside no fato de que, se por um lado a classe patronal exige um perfil de trabalhador mais escolarizado e capaz de rápidas adaptações, por outro, os trabalhadores também lutam por uma formação que responda as suas necessidades em termos de ampliação da qualificação e da escolaridade. Há uma longa história de disputa dos trabalhadores pelo acesso aos conhecimentos: "a apropriação e a manutenção do saber técnico constitui uma das 'bandeiras históricas' do movimento operário brasileiro, contra a crescente desqualificação e a expropriação do saber a que o capital o tem submetido" (MANFREDI, 2002, p.244).

Essa é a razão pela qual as centrais sindicais, a partir dos anos de 1990, deflagram um conjunto de ações em direção à ampliação da formação profissional (MANFREDI, 2002). A partir desse momento aumentam o número de cláusulas, nos contratos coletivos, que exigem formação e/ou aperfeiçoamento. Assim, a luta pela escola e acesso ao saber elaborado tem sido uma demanda de caráter não apenas técnico, mas também político.

O domínio de uma profissão e a maior ou menor escolaridade influencia as relações de força entre capital e trabalho, o que indica que se a qualificação do trabalhador é útil ao campo empresarial, pode ser ainda mais profícua ao próprio trabalhador, posto que vai na contramão do desconhecimento do conteúdo do trabalho, que se constitui num forte elemento de dominação.

\section{Os saberes e a iniciação no ofício de mecânico}

Os ofícios são constituídos por uma "cultura técnica", vinculada a um "saberfazer" particular e a experiências identitárias associadas ao trabalho. Nesses, a formação requer o exercício regular de uma atividade, envolvendo parte da aprendizagem no próprio processo laborativo. Além dos aspectos técnicos, os rituais de iniciação num ofício transmitem as regras do grupo e os sistemas de reputações e status valorizados pela coletividade.

Nesse particular, no caso dos mecânicos automotivos, observam-se alguns aspectos: as oficinas costumam ser espaços de sociabilidades que transcendem os

1 Lei $\mathrm{n}^{\text {o. }}$ 9.394, de 20 de dezembro de 1996. Disponível em: http://www2.camara.leg.br/legin/fed/lei/1996/lei-9394-20-dezembro-1996-362578-norma-pl.html (acesso em agosto, 2014). 
contornos do labor, construindo-se como lugares nos quais se combinam o trabalho e o convívio entre amigos e familiares. Ali o processo de trabalho está, em grande parte, sob o controle do trabalhador. A convivência masculina, as formas de linguagem (as "gírias de oficina"), as práticas de lazer (como o automobilismo), o manuseio das ferramentas, a valorização dos saberes práticos, são alguns dos traços que caracterizam a ocupação.

As formas de ingresso no ofício são variadas. Entre as mais usuais estão aquelas que envolvem a aprendizagem junto ao pai, parentes ou amigos, bem como as que ocorrem através de escolas profissionalizantes e instituições assistenciais.

De modo geral, aqueles que aprenderam a função de mecânico com o pai e/ou outros familiares, foram socializados, desde criança, no espaço da oficina. No horizonte desses meninos, se havia outras alternativas de futuro, elas foram, muitas vezes, suprimidas pelas “determinações concretas do meio familiar” (NAVILLE, 1975, p.141), bem como por uma determinada divisão social do trabalho correlata a uma posição de classe.

Em muitas instituições sociais perdurou a ideia, ainda influente, de que a profissão de mecânico, dado o seu maior apelo entre os homens, seria um meio especialmente eficaz de manter os jovens afastados dos "riscos sociais" da cidade. Essa é uma das razões pelas quais entidades assistenciais de Porto Alegre (RS), como é o caso do Pão dos pobres $^{2}$, passaram a oferecer cursos profissionalizantes nesta modalidade, nos quais muitas famílias pobres matriculam os jovens para que aprendam uma profissão. As instituições cumprem aqui um papel semelhante ao desempenhado pelas entidades assistenciais desde o Brasil colônia, as quais tinham a função de ensinar um ofício aos desafortunados, cujo futuro seria ocupar-se dos trabalhos manuais desvalorizados pelos demais (CUNHA, 2000).

Nos últimos anos, a profissão de mecânico, apesar de continuar a ocupar posição subalterna na hierarquia da divisão social de trabalho, tem atraído profissionais com escolaridade de nível médio técnico e/ou superior. Com a incorporação da microeletrônica aos automóveis e equipamentos de manutenção e reparação, a ocupação se tornou promissora para um grupo de homens mais escolarizados.

A possibilidade de ingressar no ofício, a partir da aprendizagem em instituições de ensino, é relativamente nova na categoria, diferenciando duas gerações de trabalhadores de oficina: a daqueles que experienciaram as transformações associadas às novas dinâmicas inauguradas nos anos 1990 (novas tecnologias automotivas, modernização dos equipamentos de reparação, eletrônica embarcada ${ }^{3}$ etc.), e a dos que ingressam no setor já sob a égide dos novos tempos, inaugurados pela reestruturação produtiva da cadeia automobilística.

${ }^{2}$ O Pão dos Pobres, fundado em 1895, é uma entidade cristã sem fins lucrativos, subsidiada por empresas, em programas de responsabilidade social, e sociedade civil, com finalidade de assistência social, oferecendo treinamentos gratuitos para menores "carentes". A entidade tem como missão inserir os "necessitados" no universo do trabalho e "oportunizar o desenvolvimento total do jovem, através de atividades que contemplam os seguintes fundamentos: alimentar o corpo, iluminar a mente, educar o coração e treinar as mãos" (Metas da entidade. Pão dos Pobres, 2011). Além do curso de mecânica automotiva, o Pão dos Pobres também oferece cursos nas áreas de marcenaria, eletricidade predial e metalurgia. Os jovens devem estar na escola regular no turno inverso para poderem ser matriculados nesses cursos. Disponível em: http://www.paodospobres.org.br/fundacao.php (acesso em fevereiro, 2011). ${ }^{3}$ A eletrônica embarcada se refere ao sistema eletrônico desenvolvido para aplicação móvel em carros, aviões, navios etc. 
É preciso esclarecer que o fato de que existe um grupo cuja forma de aprendizagem é essencialmente prática, não significa que esses sujeitos não passaram por experiências de instrução formal, pois a maioria teve acesso a cursos, palestras e/ou treinamentos. De todo modo, quando a aprendizagem no "chão da oficina" é predominante, tem-se uma forma peculiar de formação, que vai além da socialização da técnica e oferece "maneiras de fazer, sentir e pensar" (Dubar, 2009), lições de masculinidade, orgulho e honra para os meninos. Para eles, não raras vezes, a entrada na oficina absorve a maior parte do tempo das suas vidas, representando, muitas vezes, a interrupção dos estudos.

Nesses casos, os rituais de passagem na oficina demandam que se comece como "ajudante", serviço que inclui varrer, lavar peças, desmontar e montar motor. No passado, os "veteranos" relatam que até mesmo as concessionárias tinham um sistema de aprendizagem semelhante a esse. Neste modelo, efetivamente, os trabalhadores recriam, a sua maneira, uma certa unidade entre execução e concepção e preservam um saber informal.

Para aqueles cuja aprendizagem ocorreu, essencialmente, na inserção direta no processo de trabalho, foi preciso aprender "na marra", como os mecânicos costumam dizer, o que significa, na base de tentativas e erros, de forma experimental. Aprender desta maneira exige iniciativa, ousadia e curiosidade. $O$ fato de não terem passado pela escola, pelos livros, tendo no próprio corpo o instrumento de conhecimento (HARPER, 1987), faz com que parte dos mecânicos seja relutante às formas de aprendizagem mais conceituais, secundarizando o "teórico puro" e privilegiando o "modo de fazer" (CUNHA; CUNHA, 2003).

No passado, mais do que hoje, a iniciação no ofício incluía aprender a fabricar peças e ferramentas; ocorria a partir da imersão direta, passando pela relação entre pessoas e coisas, por meio do contato com os mais velhos e pela "mimesis que gera 'saberes de ação', uma 'teoria-em-ato"” (DUBAR, 2009). A aprendizagem experimental é cotidiana e requer um bom tempo para que se tenha "um ofício nas mãos"” (DUBAR, 2009), não ocorrendo sem a mediação do carisma dos colegas mais experientes.

Nesse percurso, na socialização dos valores do grupo, tem-se a valorização da própria prática e a ironização do "modo de conceituar". Não somente os "veteranos", mas muitos dos que ingressaram no ofício recentemente, têm seguido caminho semelhante, no que tange a aprendizagem. Todavia, os mais jovens, quando comparado ao passado, contam com mais acesso a cursos profissionalizantes, técnicos e outras alternativas de formação.

Uma forma muito peculiar de viver a condição de mecânico é observada entre aqueles para os quais as instituições de ensino jogaram um papel mais substancial. Eles procuram afirmar a sua autoridade não apenas a partir da habilidade presente "em carne e osso" na oficina, mas por referências a "direitos fixados no papel” (SENNETT, 2009), fazendo alusão aos certificados e diplomas que supõem provar suas expertises.

A afirmação de um dos interlocutores, segundo o qual até começar o curso técnico em automobilística de nível médio do SENAI não conhecia os automóveis embaixo do capô e "nunca tinha pegado numa chave de fenda" (entrevista, mecânico, 2011), dificilmente seria ouvida antes da reestruturação da indústria da reparação 
automotiva. A última incluiu uma maior presença de entidades de ensino determinadas a formalizar e sistematizar os conhecimentos da área 4 .

Nos anos mais recentes, o interesse de egressos do ensino superior em atuar e investir na indústria da reparação trouxe mudanças em termos de formação e na maneira de entender a atividade como um todo. Os engenheiros mecânicos, por exemplo, que saíram das faculdades e/ou da indústria para o segmento buscaram os cursos técnico e profissionalizante do SENAI e a oficina de amigos para poder "praticar". Entretanto, apesar de instruídos pelos "práticos", os "estudados" valorizam o seu percurso escolar e utilizam seus diplomas como "carta de distinção social" (DINIZ, 2001), considerandose como portadores de saberes especiais em termos de procedimentos, organização, conceitos, nomenclaturas, capacidade de diagnóstico, resolução dos problemas, entre outros. Enfatizam seus conhecimentos esotéricos, de modo a afirmar sua autoridade e ameaçar a legitimidade dos "práticos", e referem-se a si mesmo como superiores em termos técnicos, mesmo que os seus conhecimentos possam ser desnecessários - uma "qualificação supérflua" (OFFE, 1990) - na maioria dos momentos no cotidiano de trabalho, pois "não servem muito para oficina", como indica um dos mecânicos (entrevista, 2011) a respeito da formação do colega engenheiro mecânico.

Contudo, os mais escolarizados apresentam as suas credenciais como prova de "competência". Não se trata de destacar capacitação técnica, mas, sobretudo, social, sugerindo a "qualidade da pessoa", sua habilidade de "saber-ser" e não apenas de "saber-fazer". Os "estudados" distinguem-se dos "outros" e apresentam a si mesmos como mais confiáveis. Eles não deixam de usar essa "marca" para sobressaírem-se, como indicam os casos nos quais se observa a fixação do diploma de curso superior na parede da oficina.

Nas sociedades assalariadas, o ofício, embora ainda refira-se a uma maestria e especialidade, já não é o trabalho artesanal independente de outrora. Para além das formas tradicionais de aprendizagem, abre-se espaço para as escolas (DUBAR, 2005) e outros locus de formação. Nos anos recentes, os ofícios têm sido tensionados pela chegada daqueles com uma escolaridade mais elevada e que, muitas vezes, não pertencem à mesma classe nem compartilham a mesma cultura profissional, o que colabora para o que Dubar (2009) irá chamar de "crise das identidades do ofício". A "crise" decorre do fato de que os processos de aprendizagem e a socialização associada aos modos de fazer (DUBAR, 2005) passam a serem muito mais diversos e incertos do que anteriormente.

\section{Saberes práticos e saberes formais: da oficina à escola}

As distintas trajetórias de aprendizagem e acesso aos saberes práticos e formais, inauguradas pelas novas tecnologias automotivas e de reparação, não são vividas sem tensão. Parte dos mecânicos que aprendeu a profissão na prática tende a ser mais relutante com respeito à mediação das instituições de ensino. Os seus referenciais não são os conceitos e os diplomas, mas outros sujeitos que, como eles, aprenderam fazendo. Os "heróis do ofício", as "pessoas-monumentos” (CENTURIÃO, 2002, p.113),

\footnotetext{
${ }^{4}$ Os anos de 1990 correspondem ao momento no qual empresas e instituições vinculadas à indústria da reparação automotiva organizam-se de forma mais efetiva com o objetivo de reformar o setor, a exemplo da construção do SENAI-Automotivo de Porto Alegre (1999), que é uma unidade do Sistema S destinada à formação para os serviços de manutenção e reparação automotiva.
} 
são recordados pelos "veteranos" e "novatos" pelas suas "bravuras": "era um semianalfabeto... mas um grande mecânico, ele sabia tudo. Tudo assim adquirido dentro da oficina" (entrevista, mecânico, 2011).

Entre os "práticos", o mais importante é a "genialidade" astuta (DEJOURS, 1993) dos saberes "tácitos", que nem sempre se expressam em palavras, símbolos e cálculos, mas baseiam-se na experiência prévia e no improviso, na interação cotidiana (informal) entre os sujeitos e desses com os materiais, quando se desenvolve uma capacidade tácita de julgamento ("judge 'by feel”) (ISKANDER, LOWE, 2011, p.20). Não se trata, portanto, de conhecimento de papel, mas de "saber de oficina" que, por isso mesmo, serve para ser usado e resolver problema.

Para os "práticos", os "heróis do ofício" são como marco fundador de um campo de saber particular, sendo lembrados por características valorizadas na categoria, tais como garra, ousadia, curiosidade e determinação. Neste particular, recebem atenção os mecânicos preparadores de carros de corrida. Para trabalhar com preparação de automóveis de competição é preciso conhecer os metais utilizados nas peças, o tipo de solda, o formato, entre outros elementos, o que resulta em uma profunda "consciência material" (SENNETT, 2009). A ideia de que no passado os "mecânicos... eram os mágicos dos motores" (ANDREATTA; RENNER, 1992), traz um poderoso status para a categoria dos "práticos".

Durante muito tempo, sem determinação e persistência, não se fazia reparação automotiva. Na oficina, no passado como hoje, não raro o conserto ocorre a partir das conversas e discussões entre os mecânicos, através das tentativas e erros. O saber que resulta daí se constitui não na "pureza das ideias", mas junto às coisas, "na impureza permeada do material" (STALLYBRASS, 1999, p.39-40), manuseando os materiais, criando e desenvolvendo maneiras e ferramentas para lidar com eles.

Assim, não faz sentido para muitos dos interlocutores da pesquisa a existência de conhecimentos que não aqueles imbricados ao "mundo das coisas" (APPADURAI, 1986) e aos "contextos" sociais e culturais (JOVCHELOVITCH, 2008), nos quais desenvolvem suas "competências teóricas e práticas" para lidarem com as questões cotidianas.

Entre os mecânicos, as experiências diferenciadas resultam em uma cultura técnica que lança mão de uma variedade de procedimentos e metodologias (McINTYRE, 1995, p.105). Para os que estiveram longe dos bancos escolares, a busca de reconhecimento pelo "fazer do meu jeito" e o orgulho pelos saberes adquiridos na experiência direta resultam, em grande parte, do fato de que a via da aprendizagem formal lhes foi bloqueada pelo imperativo da necessidade de trabalho, que se colocou muito cedo nas suas vidas, fazendo com que muitos tivessem que parar de estudar sem terminar o ensino fundamental e/ou médio.

O "orgulho" dos práticos pelo "aprender fazendo" resulta do patrimônio que detêm enquanto grupo que "sabe fazer", em oposição ao grupo dos que "sabem falar". Para os primeiros, que construíram um repertório de conhecimentos "mesmo sob as condições adversas da sociedade capitalista" (FRIGOTTO, 2004, p.20), se o "fazer" é útil ao espaço de trabalho, então merece respeito.

Apesar de uma grande parcela dos interlocutores superestimar os saberes práticos, a chance de sair do espaço de trabalho para dedicar-se a cursos, palestras, treinamentos e à escola, é valorizada como um momento no qual se tem a chance de 
conhecer "novos ares", estabelecer contatos e aprender algo que não está absolutamente conectado com um caso específico. Nesse particular, observa-se nos depoimentos uma contradição: se, por um lado, os trabalhadores orgulham-se das suas conquistas em termos de domínio tácito do ofício, por outro, demandam acesso aos saberes conceituais sistematizados pelas instituições de ensino. Dentro da própria categoria começa a surgir um esforço geral pela busca da via formal de conhecimento, expressando uma consciência de que cada vez mais os saberes formais, certificados e títulos são utilizados para atribuir credibilidade, bem como para justificar "desigualdade social" (OFFE, 1990, p.42).

Todavia, para determinadas categorias de trabalhadores, a classe empresarial frequentemente prioriza a aprendizagem no processo produtivo, evitando a formação fora da empresa. Com relação às oficinas, com destaque para as concessionárias, os empregadores ainda temem a perda dos trabalhadores, após investirem em treinamentos e, muitas vezes, permitem o acesso aos conhecimentos "'em doses homeopáticas' [frase de Adam Smith], apenas aquele mínimo para poder operar a produção" (SAVIANI, 1994, p.161). Isso indica um reconhecimento de que a formação profissionalizante, mesmo que vinculada aos interesses de mercado, apresenta o conhecimento de forma mais ampla e contribui com a reflexão, domínio conceitual e metodológico sobre o "fazer", posto que o trabalhador apropria-se de um conhecimento menos parcial, que não é apenas o saber necessário a uma empresa em particular.

Nos dias de hoje, no caso das concessionárias, as montadoras exigem que os mecânicos passem por um percurso formativo. Em Porto Alegre a maioria das autorizadas tem convênio com o SENAI-Automotivo da capital e é a entidade que realiza os cursos. Contudo, muitas vezes, para que o trabalhador não se ausente do espaço de trabalho, as concessionárias evitam o acesso aos cursos, o que é vivido pelos mecânicos com muita frustração. Em tais circunstâncias, ao contrário de persistir a "apologia do esforço prático" indicada anteriormente, eles criticam esse tipo de restrições, evidenciando a complexidade dos processos que envolvem a valorização dos saberes.

De fato, no setor, as formas de aprendizagem têm se combinado e não ocorre a substituição de uma (velha) pela outra (nova). Contudo, os saberes elaborados formalmente e a escola como espaço de formação tencionam as regras até então predominantes no "campo da oficina" 5 , o que não ocorre de forma harmônica, mas repleto de negociações e conflitos.

\section{O conflito entre saberes e o processo de racionalização}

$\mathrm{Na}$ indústria da reparação se, por um lado, as mudanças representam uma ameaça aos "práticos", por outro, significam novas oportunidades para os mesmos. A própria noção de "práticos" tem apenas o propósito de demarcar a diferença em relação aos "estudados", e não significa que os primeiros sejam refratários às abstrações. Eles se opõem tão somente a um tipo de teoria a qual se associa uma padronização do seu trabalho. A maioria não desaprova definições conceituais, "mas rejeita a ideia de que o fluxo da informação deve seguir uma única direção" (Tradução da autora, McINTYRE,

${ }^{5}$ Para uma definição detalhada do conceito cf Ferreira (2013). 
1995, p.525), valorizando o entendimento mais completo que emerge da experiência coletiva da categoria.

No setor, a ameaça às lógicas tradicionais do ofício tem se traduzido em afrontas e ironias aos diplomados, o que tem como propósito enfraquecer a autoridade dos mesmos, fragilizando seus saberes, considerados muito peremptório.

Tais tencionamentos resultam do fato de que, diferente do que ocorreu nos períodos que precedem a reestruturação da indústria da reparação automotiva, o "campo da oficina" já não é um espaço apenas para os que "aprendem fazendo". Os "novos atores" nesse "campo" vêm munidos com outras referências, equipados com credenciais que podem ser certificadas e com discursos que priorizam os saberes adquiridos através das instituições de ensino e comprovados por meio de diplomas (HARPER, 1987). Os que veem a si mesmo como "estudados" e "modernos", condenam os chamados "amadores", por considerá-los incapazes de lidar com o universo dos softwares presentes nos automóveis e nos equipamentos de reparação, os quais demandam uma maior formalização do conhecimento.

A entrada dos "estudados" no ramo tem representado a intensificação de ações racionalizadoras que buscam padronizar, controlar e exacerbar a divisão do trabalho na oficina. Assim, se o apego dos "práticos" aos seus saberes tácitos é visto pelos reformadores do setor como conservadorismo/amadorismo, pode também ser entendido como uma forma de resistência aos processos de racionalização da oficina e, em certa medida, aos preceitos do empreendedorismo que tomam corpo no segmento.

Os movimentos de racionalização têm se dado, entre outros, pelas iniciativas de centralização da produção e transmissão do conhecimento, como evidencia a criação, em 1999, do SENAI-Automotivo de Porto Alegre/RS, destinado à formação de mecânicos. Nesse caso, a reação conservadora dos mecânicos - que remete à rebeldia de que falava Thompson (1998) ao se referir aos camponeses que resistiam à racionalização da economia de mercado -, apegados ao "fazer" e receosos das ameaças da escola, não significa que sejam relutantes aos saberes formais em si mesmos, mas sim que são relativamente temerosos ao que vem associado a eles, geralmente, um maior controle e regulação externa sobre o seu trabalho.

A "cultura técnica" do ofício, que valoriza as formas diversas de conhecer e agir, mina as imposições das reformas que visam estabelecer "centros" de aprendizagem. Para os homens do ofício os domínios dos "saberes tácitos", e da sua transmissão, significa uma forma de controle sobre o próprio trabalho.

Contudo, faz-se mister destacar que os mecânicos já não são apenas os desafortunados, cuja única chance de treinamento fora da oficina era o Pão dos Pobres e outras entidades de caridade. Eles têm tido mais acesso as instituições de ensino, o que representa, por um lado, uma oportunidade para melhorar no trabalho e na vida (KUENZER, 2011) e, por outro, é expressão do movimento de reformas racionalizantes no setor.

Entre as tensões trazidas pelos novos tempos, está o fato de que muitos dos jovens escolarizados já não compartilham os mesmos elementos da "cultura profissional" (DUBAR, 2005) tradicional da categoria. Eles são os que detêm os conhecimentos de eletrônica em oposição aos conhecimentos de mecânica; lidam com os modernos equipamentos de diagnóstico no lugar da sensibilidade dos sentidos; utilizam equipamentos eletrônicos em vez de ferramentas manuais. 
Os discursos "modernizantes", sustentados principalmente pelos mais escolarizados, fixam-se na capacidade que as tecnologias supostamente teriam de excluir os retrógrados e apostam em uma espécie de "seleção natural", na qual os mecânicos do tempo dos "carros carburados" seriam naturalmente excluídos por falta de capacidade tecnológica e empreendedora, dando lugar aos mecânicos do tempo dos "carros injetados" 6. Para aqueles que veem a si mesmos como porta vozes do "progresso" do setor, a mudança tecnológica, com a incorporação da eletrônica embarcada nos automóveis e da microeletrônica aos instrumentos de diagnósticos, é o divisor de águas que justifica a entrada no setor daqueles com maior formação técnica e capacidade de empreender.

A ênfase nos preceitos do empreendedorismo tem sido reforçada com a chegada dos mais escolarizados. O discurso de que é preciso se aperfeiçoar em termos técnicos é correlato a ideia de que se faz necessário ser mais empreendedor, seja em relação aos negócios e/ou com respeito a própria carreira. As perspectivas reformadoras, incorporadas por empresários e instituições influentes, assumem que é responsabilidade do profissional manter-se atualizado e reter um acervo de competências que possam ser mobilizadas de acordo com a preferência das empresas ou utilizadas na condução do próprio negócio, quando passa a ser importante qualificar-se e requalificar-se constantemente, quer dizer, manter-se empregável e/ou potencializar as capacidades empreendedoras.

Dessa forma, as identidades de ofício são alteradas pelas novas dinâmicas que exigem conhecimentos vinculados ao âmbito da informática e da eletrônica, bem como requererem outros recursos, como os associados às flexibilidades empreendedoras, que são mais facilmente mobilizados por atores oriundos do ensino técnico médio e/ou superior.

O que está em jogo com a dramatização e desestabilidade das referências identitárias anteriores é todo o modelo de ofício, capaz de incluir os modos de vida, trabalho e conduta que caracterizaram a atividade até então. A partir de novas construções identitárias, afirmam-se outras fronteiras e hierarquias entre os sujeitos, as quais têm destacado supostas diferenças em termos de competências técnicas. $O$ fato de que as transformações demandam do trabalhador um maior envolvimento analítico, faz com que surja um novo repertório técnico: fala-se em chips, sensores, leituras digitais, computadores e outras referências não mais mecânicas. As mudanças alteram o conhecimento sociotécnico que definia o mecânico, frustrando alguns e/ou criando novas chances para outros, posto que têm representado oportunidade, desafio e/ou exclusão, dependendo dos recursos dos sujeitos.

No âmbito das transformações da indústria da reparação automotiva, a ênfase nas abstrações conceituais e graus escolares reforça a discriminação dos trabalhadores com experiência anterior, mas "precariamente escolarizados" (KUENZER, 2003). A referência a "falta de" escolaridade tem sido usada para desqualifica-los, "empurrandoos para baixo ou remetendo-os à exclusão" (PAIVA, 1991, p.84), ao enquadra-los na categoria de intelectualmente incapazes.

O questionamento dos modelos de ofício, até então preponderantes, oferece outras "modalidades de identificação" (DUBAR; DEMAZIÈRE, 2000), colocando em

6 A expressão "carros carburados" refere-se aos automóveis com carburadores, enquanto "carros injetados" aos veículos com injeção eletrônica. 
xeque a relativa estabilidade das formas de pertencimento anteriores. As novas construções identitárias ocorrerem tendo em conta o fato de que o trabalho requer competências mais cognitivas do que manuais, o que faz com que as referências valorativas passem a ser mais vinculada a capacidade de diagnosticar do que de executar o trabalho.

Frente a isso, se, por um lado, os homens do ofício resistem a secundarização dos seus "saberes tácitos", porque sabem que desses dependem o seu controle sobre o próprio trabalho, por outro, aspiram aos domínios conceituais, reconhecidos como socialmente valorizados.

\section{Considerações finais}

No decorrer do processo de reestruturação da indústria da reparação automotiva, a "cultura técnica" do ofício de mecânico ligada, sobretudo, aos "saberes práticos" e construída em sintonia com os objetos que compõem a materialidade da vida na oficina, defronta-se com a necessidade de incorporar referências que passam pela linguagem dos softwares e dos computadores, estabelecendo mudanças nas formas e conteúdos dos saberes, bem como novas sociabilidades, modos de ser e de trabalhar.

O debate proposto sobre a natureza dos saberes, em geral, e do ofício dos mecânicos, em particular, elucida que os conhecimentos técnicos não são neutros, posto que vinculados a relações culturais e sociais mais amplas. Nesse particular, a entrada nas oficinas de sujeitos mais escolarizados tem intensificado os processos de racionalização do trabalho, contribuindo, em grande parte, para a rejeição da formalização do conhecimento por parte dos "práticos".

Em resumo, o texto indicou a forma pela qual as novas tecnologias incorporadas aos automóveis e aos equipamentos de manutenção e reparação vieram de mãos dadas com outras e variadas formas de saber, socialização e percepção de mundo.

Nesse interim uma identidade de ofício, baseada em hábitos há muito tempo legitimados, é afrontada por transformações que incluem uma maior relevância dos saberes abstratos e, mais do que isso, envolvem novas posturas e modos de viver e trabalhar, intensificando a presença da noção de empreendedorismo, quando argumentase que é preciso ser empreendedor para manter-se atualizado e adaptado em termos de conhecimentos técnicos e de gestão empresarial.

Com isso, os ideais de empreendedorismo e a concepção de que a empresa de hoje precisa de um profissional capaz de garantir sua empregabilidade ganham força com a presença dos "estudados", abalando as identidades de ofício até então preponderantes no segmento da reparação automotiva.

\section{Referências}

ANDREATTA, L. F; RENNER, P.R. Automobilismo no tempo das carreteras. Porto Alegre: Ed. do Autor, 1992.

APPADURAI, A. The social life of things: Commodities in cultural perspective. Cambridge: Cambridge University Press, 1986.

CENTURIÃO, L. R. Identidade, indivíduo e grupos sociais. Curitiba: Juruá, 2002. 
CUNHA, L. A. O ensino industrial-manufatureiro no Brasil. In: Revista Brasileira de Educação. Mai/Jun/Jul/Ago., n 14, 2000.

CUNHA, M. M; CUNHA, L. C. A identidade profissional e a preparação para o trabalho no centro de formação profissional de Santa Maria (RRFSA/ SENAI). In: Educação (Santa Maria). Santa Maria, RS. Vol. 28, n. 2, 2003.

DEJOURS, C. Inteligência operária e organização do trabalho: A propósito do modelo japonês de produção. In: HIRATA, Helena (Org.). Sobre o 'Modelo Japonês': Automatização, novas formas de organização e de relações de trabalho. São Paulo: Editora da Universidade de São Paulo, 1993.

DINIZ, M. Os donos do saber: profissões e monopólios profissionais. Rio de Janeiro: Renavan, 2001.

DUBAR, C.; DEMAZIÈRE, D. Trajetória profissional e formas identitárias: uma teorização. In: Contemporaneidade e Educação. Ano V, nº 8. $2^{\circ}$ Sem., 2000.

DUBAR, C. A crise das identidades: A interpretação de uma mutação. São Paulo: Editora da Universidade de São Paulo, 2009.

DUBAR, C. A socialização: construção das identidades sociais e profissionais. São Paulo: Martins Fontes, 2005.

FERREIRA, L. S. (2013), Processos de resistência e novos desenhos identitários: o ofício do mecânico e a racionalização da indústria da reparação automotiva. Tese (Doutorado em Sociologia). Instituto de Filosofia e Ciências Sociais, Universidade Federal do Rio de Janeiro.

FRANZOI, N. L. O conhecimento informal dos trabalhadores no chão de fábrica. In: Educação Unisinos. Volume 13, número 3, setembro/dezembro, 2009.

FRIGOTTO, G. Trabalho, conhecimento, consciência e a educação do trabalhador: Impasses teórico e prático. In: GOMES, Carlos Minayo et al. (Org.). Trabalho e conhecimento: Dilemas na educação do trabalhador. São Paulo: Editora Cortez, 2004.

HARPER, D. Working knowledge: Skill and community in a small shop. Chicago: University of Chicago Press, 1987.

ISKANDER, N.; LOWE, N. The transformers: Immigration and localized knowledge development. NYU Wagner Research Paper. No 1, 2011.

JOVCHELOVITCH, S. Os contextos do saber: representações, comunidade e cultura. Petrópolis: Vozes, 2008.

KUENZER, A. As relações entre conhecimento tácito e conhecimento científico a partir da base microeletrônica: primeiras aproximações. In: Educar. Curitiba, Especial, Editora UFPR, 2003.

KUENZER, A. Pedagogia da fábrica. As relações de produção e a educação do trabalhador. São Paulo: Cortez, 2011.

MACHADO, L. R. Educação e divisão social do trabalho: contribuição para o estudo do ensino técnico industrial. São Paulo: Autores Associados: Cortez, 1989.

MANFREDI, S. M. Educação profissional no Brasil. São Paulo: Cortez, 2002.

McINTYRE, S. L. The repair man will gyp you: Mechanics, managers, and customers in the automobile repair industry, 1986-1940. Columbia: University of Missouri-Columbia, 1995.

NAVILLE, P. Teoria da orientação profissional. Lisboa: Estampa, 1975. 
OFFE, C. Sistema educacional, sistema ocupacional e política da educação Contribuição à determinação das funções sociais do sistema educacional. In: Educação \& Sociedade. n.35, abril, 1990.

PAIVA, V. Produção e qualificação para o trabalho: uma revisão da bibliografia internacional. In: DIAS, Fernando Correia (Org.). Ensino das humanidades: a modernidade em questão. São Paulo: Cortez: Brasília: SENEB, 1991.

SAVIANI, D. O trabalho como princípio educativo frente às novas tecnologias. In: FERRETTI, Celso João et al. (Org.). Novas tecnologias, trabalho e educação: Um debate multidisciplinar. Petrópolis: Vozes, 1994.

SENNETT, R. O artífice. Rio de Janeiro: Record, 2009.

STALLYBRASS, P. O casaco de Marx: roupas, memórias, dor. Belo Horizonte: Autêntica, 1999.

SZNELWAR, L.; MASCIA, F. A inteligência (não reconhecida) do trabalho. In: ARBIX, Glauco; ZILBOVICIUS, Mauro (Org.). De JK a FHC, a reinvenção dos carros. São Paulo: Scritta, 1997.

THOMPSON, E. P. Costumes em comum. São Paulo: Cia das Letras, 1998.

WILLIS, P. Learning to labour: How working class kids get working class Jobs. England: Saxon House, 1977. 